\title{
Accounting for the U.S. Earnings and Wealth Inequality
}

\author{
Ana Castañeda \\ BNP Paribas Securities Services \\ Javier Díaz-Giménez \\ Universidad Carlos III de Madrid \\ José-Víctor Ríos-Rull \\ University of Pennsylvania, Centro de Altísimos Estudios Ríos Pérez, National Bureau of \\ Economic Research, and Centre for Economic Policy Research
}

\begin{abstract}
We show that a theory of earnings and wealth inequality, based on the optimal choices of ex ante identical households that face uninsured idiosyncratic shocks to their endowments of efficiency labor units, accounts for the U.S. earnings and wealth inequality almost exactly.
\end{abstract}

Ríos-Rull thanks the National Science Foundation for grant SBR-9309514 and the University of Pennsylvania Research Foundation for its support. Díaz-Giménez thanks the Banco de Santander Central Hispano, the Dirección General de Investigación Ciencia y Tecnología for grant 98-0139, Amparo Pla Carretero, and Andoni. We thank Dirk Krueger for the data on the distribution of consumption. The comments and suggestions of the many colleagues that have discussed this article with us over the years and those of the editor and an anonymous referee are also gratefully acknowledged.

[Journal of Political Economy, 2003, vol. 111, no. 4]

(C) 2003 by The University of Chicago. All rights reserved. 0022-3808/2003/11104-0005 $\$ 10.00$ 


\section{Introduction}

The project.-Redistribution of wealth is a central issue in the discussion of economic policy. It is also one of the arguments most frequently used to justify the intervention of the government. In spite of its importance, formal attempts to evaluate the distributional implications of policy have had little success. The main reason is that researchers have failed to come up with a quantitative theory that accounts for the observed earnings and wealth inequality in sufficient detail. The purpose of this article is to provide such a theory.

The facts.-In the U.S. economy, the distributions of earnings and, especially, of wealth are very concentrated and skewed to the right. For instance, their Gini indexes are 0.63 and 0.78 , respectively, and the shares of earnings and wealth of the households in the top 1 percent of the corresponding distributions are 15 percent and 30 percent, respectively. ${ }^{1}$

The question.-In this article we ask whether we can construct a theory of earnings and wealth inequality, based on the optimal choices of ex ante identical households that face uninsured idiosyncratic shocks to their endowments of efficiency labor units, that accounts for the U.S. distributions of earnings and wealth. We find that we can.

Previous answers.-Quadrini and Ríos-Rull (1997) review the quantitative attempts to account for earnings and wealth inequality until that date, and they show that every article that studies the decisions of households with identical preferences has serious problems in accounting for the shares of earnings and of wealth of the households in both tails of the corresponding distributions. Later work suffers from milder versions of the same problems: it fails to account both for the extremely long and thin top tails of the distributions and for the large number of households in their bottom tails. These results lead us to conclude that a quantitative theory of earnings and wealth inequality that can be used to evaluate the distributional implications of economic policy is still in the works.

This article.-Our theory of earnings and wealth inequality is based on the optimal choices of households with identical and standard preferences. These households receive an idiosyncratic random endowment of efficiency labor units, they do not have access to insurance markets, and they save, in part, to smooth their consumption. In relation to

\footnotetext{
${ }^{1}$ These facts and the points of the Lorenz curves of earnings and wealth reported in table 2 below have been obtained using data from the 1992 Survey of Consumer Finances (SCF). They are reported in Díaz-Giménez, Quadrini, and Ríos-Rull (1997), and they are confirmed by many other empirical studies (see, e.g., Lillard and Willis 1978; Wolff 1987; Hurst, Luoh, and Stafford 1998).
} 
previous work, we make three major changes to the way in which this basic theory is implemented. These changes pertain to the design of our model economy and to our calibration procedure: (i) We mix the main features of the dynastic and of the life cycle abstractions. More specifically, we assume that the households in our model economies are altruistic and that they go through the life cycle stages of working age and retirement. These features give our households two additional reasons to save: to supplement their retirement pensions and to endow their estates. They also help us to account for the top tail of the wealth distribution. (ii) We model explicitly some of the quantitative properties of the U.S. Social Security system. This feature gives our earnings-poor households few incentives to save. It also helps us to account for the bottom tail of the wealth distribution. (iii) We calibrate our model economy to the Lorenz curves of U.S. earnings and wealth as reported by the 1992 SCF. We do this instead of measuring the process on earnings directly, as is standard in the literature. This feature allows us to obtain a process on earnings that is consistent with both the aggregate and the distributional data on earnings and wealth. It also enables the earningsrich households in our model economy to accumulate sufficiently large amounts of wealth sufficiently fast.

Two additional features that distinguish our model economy from those in the literature are as follows: (iv) We model the labor decision explicitly, and (v) we replicate the progressivity of the U.S. income and estate tax systems. The first of these two features is important because the ultimate goal of our study of inequality is to evaluate the distributional implications of fiscal policy, and doing this in models that do not study the labor decision explicitly makes virtually no sense. The second feature is important because progressive income and estate taxation distorts the labor and savings decisions, discouraging earnings-rich households both from working long hours and from accumulating large quantities of wealth. Therefore, the fact that we succeed in accounting for the observed earnings and wealth inequality, in spite of the disincentives created by progressive taxation, increases our confidence in the usefulness of our theory.

In the last part of this article, we use our model economy to study the roles played by the life cycle profile of earnings and by the intergenerational transmission of earnings ability in accounting for earnings and wealth inequality, and finally, we use it to quantify the steady-state implications of abolishing estate taxation.

Findings.-We show that our model economy can be calibrated to the main U.S. macroeconomic aggregates, to the U.S. progressive income and estate tax systems, and to the Lorenz curves of both earnings and wealth, and we find that there is a four-state Markov process on the endowment of efficiency labor units that accounts for the U.S. distri- 
butions of earnings and wealth almost exactly. This process on the earnings potential of households is persistent, and the differences in the values of its realizations are large. ${ }^{2}$

As an additional test of our theory, we compare its predictions with respect to two sets of overidentifying restrictions: the earnings and wealth mobility of U.S. households and the U.S. distribution of consumption. With respect to mobility, we find that our model economy accounts for some of its qualitative features but that, quantitatively, our model economies' mobility statistics differ from their U.S. counterparts. With respect to the distribution of consumption, we find that our model economy does a good job of accounting for the quantitative properties of the U.S. distribution of this variable.

We also find that, even though the roles played by the intergenerational transmission of earnings ability and the life cycle profile of earnings are quantitatively significant, they are not crucial to accounting for the U.S. earnings and wealth inequality.

Finally, as far as the policy experiment of abolishing estate taxation is concerned, we find that the steady-state implications of this policy change are to increase output by 0.35 percent and the stock of capital by 0.87 percent, and that its distributional implications are very small.

Sectioning.-The rest of the article is organized as follows: In Section II, we summarize some of the previous attempts to account for earnings and wealth inequality, and we justify our modeling choices. In Section III, we describe our benchmark model economy. In Section IV, we discuss our calibration strategy. In Section V, we report our findings, and we quantify the roles played by the intergenerational transmission of earnings ability and the life cycle profile of earnings in accounting for inequality. In Section VI, we evaluate the steady-state implications of abolishing estate taxation, and in Section VII, we offer some concluding comments.

\section{Previous Literature and the Rationale for Our Modeling Choices}

In this section we summarize the findings of Aiyagari (1994), Huggett (1996), Quadrini (1997), Castañeda, Díaz-Giménez, and Ríos-Rull (1998a), Krusell and Smith (1998), De Nardi (1999), and Domeij and Klein (2000). ${ }^{3}$ Those articles share the following features: (i) they attempt to account for the earnings and wealth inequality; (ii) they study

\footnotetext{
${ }^{2}$ These two properties are features of the shocks faced by young households when they enter the labor market. This result suggests that the circumstances of people's youth play a significant role in determining their economic status as adults.

${ }^{3}$ For a detailed discussion of the contributions made in the first four of these articles, see Quadrini and Ríos-Rull (1997).
} 
TABLE 1

Distributions of Earnings and of Wealth in the United States and in Selected Model Economies

\begin{tabular}{|c|c|c|c|c|}
\hline & Gini & Bottom $40 \%$ & Top 5\% & Top $1 \%$ \\
\hline & \multicolumn{4}{|c|}{ A. U.S. Economy } \\
\hline Earnings & .63 & 3.2 & 31.2 & 14.8 \\
\hline \multirow[t]{2}{*}{ Wealth } & .78 & 1.7 & 54.0 & 29.6 \\
\hline & \multicolumn{4}{|c|}{ B. Aiyagari (1994) } \\
\hline Earnings & .10 & 32.5 & 7.5 & 6.8 \\
\hline \multirow[t]{2}{*}{ Wealth } & .38 & 14.9 & 13.1 & 3.2 \\
\hline & \multicolumn{4}{|c|}{ C. Castañeda et al. (1998) } \\
\hline Earnings & .30 & 20.6 & 10.1 & 2.0 \\
\hline \multirow[t]{2}{*}{ Wealth } & .13 & 32.0 & 7.9 & 1.7 \\
\hline & \multicolumn{4}{|c|}{ D. Quadrini (1998) } \\
\hline \multirow{3}{*}{$\begin{array}{l}\text { Earnings } \\
\text { Wealth }\end{array}$} & & $\ldots$ & & \\
\hline & .74 & $\ldots$ & 45.8 & 24.9 \\
\hline & \multicolumn{4}{|c|}{ E. Krusell and Smith (1998) } \\
\hline \multirow{3}{*}{$\begin{array}{l}\text { Earnings } \\
\text { Wealth }\end{array}$} & $\ldots$ & $\ldots$ & 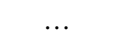 & $\ldots$ \\
\hline & .82 & $\ldots$ & 55.0 & 24.0 \\
\hline & \multicolumn{4}{|c|}{ F. Huggett (1996) } \\
\hline Earnings & .42 & 9.8 & 22.6 & 13.6 \\
\hline \multirow[t]{2}{*}{ Wealth } & .74 & .0 & 33.8 & 11.1 \\
\hline & \multicolumn{4}{|c|}{ G. De Nardi (1999) } \\
\hline Earnings & & & & \\
\hline Wealth & .61 & 1.0 & 38.0 & 15.0 \\
\hline
\end{tabular}

the decisions of households that face a process on labor earnings that is random, household-specific, and noninsurable; and (iii) the households in their model economies accumulate wealth in part to smooth their consumption. We report some of their quantitative findings in table 1 .

Aiyagari (1994), Quadrini (1997), Castañeda et al. (1998a), and Krusell and Smith (1998) model purely dynastic households. Aiyagari measures the process on earnings using the Panel Study of Income Dynamics (PSID) and other sources, and he obtains distributions of earnings and wealth that are too disperse (see panel B of table 1). Castañeda et al. partition the population into five household types that are subject to type-specific employment processes, and they find that permanent earnings differences play a very small role in accounting for wealth inequality. Quadrini explores the role played by entrepreneurship in accounting for wealth inequality and economic mobility, and he finds that this role is key. His model economy does not account for the earnings and wealth distributions completely, but it accounts for the fact that the wealth to 
income ratios of entrepreneurs are significantly higher than those of workers. Finally, Krusell and Smith use shocks to the time discount rates in their attempt to account for the observed wealth inequality. This feature distinguishes their work from the rest of the articles discussed in this section-which study the decisions of households with identical preferences-and it allows Krusell and Smith to do a fairly good job of accounting for the Gini index and for the share of wealth owned by the households in the top 5 percent of the wealth distribution (see panel $\mathrm{E}$ of table 1).

Huggett (1996) studies a purely life cycle model. He calibrates the process on earnings using different secondary sources, and he includes a social security system that pays a lump-sum pension to retirees. The Gini indexes of the distributions of earnings and wealth of his model economy are higher than those in most of the other articles discussed in this section, partly because of the very large number of households with negative wealth. Moreover, he also falls short of accounting for the share of wealth owned by the households in the top 5 percent of the wealth distribution (see panel $\mathrm{F}$ of table 1).

In a recent working paper, De Nardi (1999) studies a life cycle model economy with intergenerational transmission of genes and joy-of-giving bequests. This is a somewhat ad hoc way of modeling altruism, and it makes her results difficult to evaluate. It is hard to tell how much joy of giving is appropriate, and it is not clear whether her parameterization implies that her agents care more, less, or the same for their children than for themselves. With the significant exception of the top 1 percent of the wealth distribution, she comes reasonably close to accounting for the wealth inequality observed in the United States (see panel G of table $1)$.

Finally, in a very recent working paper, Domeij and Klein (2000) study an overlapping generations model without leisure that follows people well into their old age. They find that a generous pension scheme is essential to accounting for distributions of wealth that are significantly concentrated. ${ }^{4}$ In accordance with Huggett (1996) and the pure life cycle tradition, Domeij and Klein also find that the share of wealth owned by the very wealthy households in their model economy is much smaller than in the data. The reason is that in model economies that abstract from altruism, the old do not have enough reasons to save, and consequently, they end up consuming most of their wealth before they die.

\footnotetext{
${ }^{4}$ In contrast to the rest of the papers discussed in this section, Domeij and Klein attempt to account for income and wealth inequality in Sweden. Even though the earnings and wealth inequality is smaller in Sweden than in the United States, the distributions of income and wealth in Sweden, like their U.S. counterparts, are significantly concentrated and skewed to the right.
} 
This brief literature review shows that both purely dynastic and purely life cycle model economies fail to generate enough savings to account for wealth inequality. In purely dynastic models the main reason is that the wealth to earnings ratios of the earnings-rich are too low, and those of the earnings-poor are too high. In purely life cycle models the main reason is that households have neither the incentives nor the time to accumulate sufficiently large amounts of wealth. To overcome these problems, the model economy that we study in this article includes the main features of both abstractions-namely, retirement and bequests.

Our review of the literature also shows that theories that abstract from social security result in wealth to earnings ratios of the households in the bottom tails of the distributions that are too high. To overcome this problem, our model economy includes an explicit pension system that reduces the life cycle savings of the earnings-poorest.

Another important conclusion that arises from our review of the literature is that attempts to measure the process on earnings directly, using sources that do not oversample the rich and are subject to a significant amount of top-coding, misrepresent the income of the highest earners and fail to deliver the U.S. distribution of earnings as measured by the SCF. Since, in those theories, the earnings of highly productive households are much too small, it is hardly surprising that the earnings-rich households of their model economies fail to accumulate enough wealth. To overcome this problem, in this article we use the Lorenz curves of both earnings and wealth to calibrate the process on the endowment of efficiency labor units faced by our model economy households. We find that this procedure allows us to account for the U.S. distributions of earnings and wealth almost exactly.

Finally, in a previous version of this article (see Castañeda et al. 1998b), we found that progressive income taxation plays an important role in accounting for the observed earnings and wealth inequality. Specifically, in that article we study two calibrated model economies that differ only in the progressivity of their income tax rates-in one of them they reproduce the progressivity of U.S. effective rates, and in the other one they are constant-and we find that their distributions of wealth differ significantly. ${ }^{5}$ We concluded that theories that abstract from the labor decision and from progressive income taxation make it significantly easier for earnings-rich households to accumulate large quantities of wealth. The reason is that in those model economies, both the aftertax wage and the after-tax rate of return are significantly larger than those observed, and this disparity exaggerates their ability to account

\footnotetext{
${ }^{5}$ For example, the steady-state share of wealth owned by the households in the top 1 percent of the wealth distribution increases from 29.5 percent to 39.0 percent, the share owned by those in the bottom 60 percent decreases from 3.8 percent to 0.1 percent, and the Gini index increases from 0.79 to a startling 0.87 .
} 
for the observed wealth inequality. To overcome this problem, in our model economy, the labor decision is endogenous, and we include ex-

plicit income and estate tax systems that replicate the progressivities of their U.S. counterparts.

In summary, our literature review leads us to conclude that previous attempts to account for the observed earnings and wealth inequality have failed to provide us with a theory in which households have identical and standard preferences, in which the earnings process is consistent both with the U.S. aggregate earnings and with the U.S. earnings distribution, and in which the tax system resembles the U.S. tax system. In this article we provide such a theory.

\section{The Model Economy}

The model economy analyzed in this article is a modified version of the stochastic neoclassical growth model with uninsured idiosyncratic risk and no aggregate uncertainty. The key features of our model economy are as follows: (i) it includes a large number of households with identical preferences; (ii) households face an uninsured, household-specific shock to their endowments of efficiency labor units; (iii) households go through the life cycle stages of working age and retirement; (iv) retired households face a positive probability of dying, and when they die, they are replaced by a working-age descendant; and (v) households are altruistic toward their descendants.

\section{A. The Private Sector}

1. Population Dynamics and Information

We assume that our model economy is inhabited by a continuum of households. The households either can be of working age or can be retired. Working-age households face an uninsured idiosyncratic stochastic process that determines the value of their endowment of efficiency labor units. They also face an exogenous and positive probability of retiring. Retired households are endowed with zero efficiency labor units. They also face an exogenous and positive probability of dying. When a retired household dies, it is replaced by a working-age descendant that inherits the deceased household estate, if any, and, possibly, some of its earning abilities. We use the one-dimensional shock, s, to denote the household's random age and random endowment of efficiency labor units jointly (for details on this process, see Secs. IIIA2 and IVA2 below). We assume that this process is independent and identically distributed across households and that it follows a finite state Markov 
chain with conditional transition probabilities given by $\boldsymbol{\Gamma}_{S S}=\boldsymbol{\Gamma}\left(s^{\prime} \mid s\right)=$ $\operatorname{Pr}\left\{s_{t+1}=s^{\prime} \mid s_{t}=s\right\}$, where $s$ and $s^{\prime} \in S=\left\{1,2, \ldots, n_{s}\right\}$.

\section{Employment Opportunities}

We assume that every household is endowed with $\ell$ units of disposable time and that the joint age and endowment shock $s$ takes values in one of two possible $J$-dimensional sets, $s \in S=\varepsilon \cup \mathcal{R}=\{1,2, \ldots, J\} \cup\{J+$ $1, J+2, \ldots, 2 J\}$. When a household draws shock $s \in \mathcal{E}$, we say that it is of working age, and we assume that it is endowed with $e(s)>0$ efficiency labor units. When a household draws shock $s \in \mathcal{R}$, we say that it is retired, and we assume that it is endowed with zero efficiency labor units. We use the $s \in \mathbb{R}$ to keep track of the realization of $s$ that the household faced during the last period of its working life. This knowledge is essential to analyze the role played by the intergenerational transmission of earnings ability in this class of economies.

The notation described above allows us to represent every demographic change in our model economy as a transition between the sets $\varepsilon$ and $\mathcal{R}$. When a household's shock changes from $s \in \mathcal{E}$ to $s^{\prime} \in \mathcal{R}$, we say that it has retired. When it changes from $s \in \mathcal{R}$ to $s^{\prime} \in \mathcal{E}$, we say that it has died and has been replaced by a working-age descendant. Moreover, this specification of the joint age and endowment process implies that the transition probability matrix $\boldsymbol{\Gamma}_{S S}$ controls (i) the demographics of the model economy by determining the expected durations of the households' working lives and retirements, (ii) the lifetime persistence of earnings by determining the mobility of households between the states in $\mathcal{E}$, (iii) the life cycle pattern of earnings by determining how the endowments of efficiency labor units of new entrants differ from those of senior working-age households, and (iv) the intergenerational persistence of earnings by determining the correlation between the states in $\varepsilon$ for consecutive members of the same dynasty. In Section IVA2 we discuss these issues in detail.

\section{Preferences}

We assume that households value both their consumption and their leisure and that they care about the utility of their descendants as much as they care about their own utility. Consequently, the households' preferences can be described by the following standard expected utility function:

$$
E\left[\sum_{t=0}^{\infty} \beta^{t} u\left(c_{t}, \ell-l_{t}\right) \mid s_{0}\right],
$$


where the function $u$ is continuous and strictly concave in both arguments, $0<\beta<1$ is the time discount factor, $c_{t} \geq 0$ is consumption, $\ell$ is the endowment of productive time, and $0 \leq l_{t} \leq \ell$ is labor. Consequently, $\ell-l_{t}$ is the amount of time that the households allocate to nonmarket activities.

\section{Production Possibilities}

We assume that aggregate output, $Y_{t}$, depends on aggregate capital, $K_{t}$, and on the aggregate labor input, $L_{t}$, through a constant returns to scale aggregate production function, $Y_{t}=f\left(K_{t}, L_{t}\right)$. Aggregate capital is obtained aggregating the wealth of every household, and the aggregate labor input is obtained aggregating the efficiency labor units supplied by every household. We assume that capital depreciates geometrically at a constant rate, $\delta$.

\section{Transmission and Liquidation of Wealth}

We assume that every household inherits the estate of the previous member of its dynasty at the beginning of the first period of its working life. Specifically, we assume that when a retired household dies, it does so after that period's consumption and savings have taken place. At the beginning of the following period, the deceased household's estate is liquidated, and the household's descendant inherits a fraction $1-$ $\tau_{E}\left(z_{t}\right)$ of this estate. The rest of the estate is instantaneously and costlessly transformed into the current-period consumption good, and it is taxed away by the government. Note that the variable $z_{t}$ denotes the value of the household's stock of wealth at the end of period $t$.

\section{B. The Government Sector}

We assume that the government in our model economies taxes households' income and estates and that it uses the proceeds of taxation to make real transfers to retired households and to finance its consumption. Income taxes are described by the function $\tau\left(y_{t}\right)$, where $y_{t}$ denotes household income; estate taxes are described by the function $\tau_{E}\left(z_{t}\right)$; and public transfers are described by the function $\omega\left(s_{t}\right)$. Therefore, in our model economies, a government policy rule is a specification of $\left\{\tau\left(y_{t}\right)\right.$, $\left.\tau_{E}\left(z_{t}\right), \omega\left(s_{t}\right)\right\}$ and of a process on government consumption, $\left\{G_{t}\right\}$. Since we also assume that the government must balance its budget every period, these policies must satisfy the following restriction:

$$
G_{t}+T_{t}=T_{t}
$$


where $T r_{t}$ and $T_{t}$ denote aggregate transfers and aggregate tax revenues, respectively. ${ }^{6}$

\section{Market Arrangements}

We assume that there are no insurance markets for the householdspecific shock. ${ }^{7}$ Moreover, we also assume that the households in our model economy cannot borrow. ${ }^{8}$ Partly to buffer their streams of consumption against the shocks, households can accumulate wealth in the form of real capital, $a_{t}$. We assume that these wealth holdings belong to a compact set $\mathcal{A}$. The lower bound of this set can be interpreted as a form of liquidity constraints or, alternatively, as the solvency requirement mentioned above. The existence of an upper bound for the asset holdings is guaranteed as long as the after-tax rate of return to savings is smaller than the households' common rate of time preference (see Huggett [1993], Aiyagari [1994], and Ríos-Rull [1999] for details). This condition is satisfied in every model economy that we study. Finally, we assume that firms rent factors of production from households in competitive spot markets. This assumption implies that factor prices are given by the corresponding marginal productivities.

\section{Equilibrium}

Each period the economywide state is a measure of households, $x_{t}$, defined over $\mathscr{B}$, an appropriate family of subsets of $\{S \times \mathcal{C}\}$. As far as each individual household is concerned, the state variables are the realization of the household-specific shock, $s_{t}$, its stock of wealth, $a_{t}$, and the aggregate state variable, $x_{i}$. However, for the purposes of this article,

\footnotetext{
${ }^{6}$ Note that social security in our model economy takes the form of transfers to retired households and that these transfers do not depend on past contributions made by the households. We make this assumption in part for technical reasons. Discriminating between the households according to their past contributions to a social security system requires the inclusion of a second asset-type state variable in the household decision problem, and this increases the computational costs significantly.

${ }^{7}$ This is a key feature of this class of model worlds. When insurance markets are allowed to operate, our model economies collapse to a standard representative household model, as long as the right initial conditions hold. In a recent article, Cole and Kocherlakota (1997) study economies of this type with the additional characteristic that private storage is unobservable. They conclude that the best achievable allocation is the equilibrium allocation that obtains when households have access to the market structure assumed in this article. We interpret this finding to imply that the market structure that we use here could arise endogenously from certain unobservability features of the environmentspecifically, from the unobservability of both the realization of the shock and the amount of wealth.

${ }^{8}$ Given that leisure is an argument in the households' utility function, this borrowing constraint can be interpreted as a solvency constraint that prevents the households from going bankrupt in every state of the world.
} 
it suffices to consider only the steady states of the market structure described above. These steady states have the property that the measure of households remains invariant, even though both the state variables and the actions of the individual households change from one period to the next. This implies that, in a steady state, the individual households' state variable is simply the pair $\left(s_{t}, a_{t}\right)$. Since the structure of the households' problem is recursive, henceforth we drop the time subscript from all the current-period variables, and we use primes to denote the values of variables one period ahead.

\section{The Households' Decision Problem}

The dynamic program solved by a household whose state is $(s, a)$ is

$$
\begin{gathered}
v(s, a)=\max _{c \geq 0, z \in \mathcal{C}, 0 \leq \leq \leq \ell}\left\{u(c, \ell-l)+\beta \sum_{s^{\prime} \in S} \boldsymbol{\Gamma}_{s s^{\prime}} v\left[s^{\prime}, a^{\prime}(z)\right]\right\} \\
\text { subject to } c+z=y-\tau(y)+a, \\
y=a r+e(s) l w+\omega(s), \\
a^{\prime}(z)= \begin{cases}z-\tau_{E}(z) & \text { if } s \in \mathcal{R} \text { and } s^{\prime} \in \mathcal{E} \\
z & \text { otherwise, }\end{cases}
\end{gathered}
$$

where $v$ denotes the households' value function, $r$ denotes the rental price of capital, and $w$ denotes the wage rate. Note that the definition of income, $y$, includes three terms: capital income, which can be earned by every household; labor income, which can be earned only by workingage households (recall that $e(s)=0$ when $s \in \mathcal{R}$ ); and social security income, which can be earned only by retired households (recall that $\omega(s)=0$ when $s \in \mathcal{E}$ ). The household policy that solves this problem is a set of functions that map the individual state into choices for consumption, gross savings, and hours worked. We denote this policy by $\{c(s, a), z(s, a), l(s, a)\}$.

\section{Definition of Equilibrium}

A steady-state equilibrium for this economy is a household value function, $v(s, a)$; a household policy, $\{c(s, a), z(s, a), l(s, a)\}$; a government policy, $\left\{\tau(y), \tau_{E}(z), \omega(s), G\right\}$; a stationary probability measure of households, $\mathbf{x}$; factor prices, $(r, w)$; and macroeconomic aggregates, $\{K, L, T$, $T r$, such that the following conditions hold: (i) Factor inputs, tax revenues, and transfers are obtained aggregating over households:

$$
K=\int a d \mathbf{x},
$$




$$
\begin{gathered}
L=\int l(s, a) e(s) d \mathbf{x}, \\
T=\int \tau(y) d \mathbf{x}+\int \xi_{s \in \mathcal{R}} \boldsymbol{\gamma}_{s \varepsilon} \tau_{E}(z) z(s, a) d \mathbf{x}, \\
T r=\int \omega(s) d \mathbf{x},
\end{gathered}
$$

where household income, $y(s, a)$, is defined in equation (5); $\xi$ denotes the indicator function; $\boldsymbol{\gamma}_{s \varepsilon} \equiv \sum_{s^{\prime} \in \mathcal{E}} \boldsymbol{\Gamma}_{s, s^{\prime}}$; and, consequently, $\boldsymbol{\xi}_{s \in \mathcal{R}} \boldsymbol{\gamma}_{s \varepsilon}$ is the probability that a type $s$ household dies; recall that this probability is zero when $s \in \mathcal{E}$, since we have assumed that working-age households do not die. All integrals are defined over the state space $S \times \mathcal{C}$. (ii) Given $\mathbf{x}, K, L, r$, and $w$, the household policy solves the households' decision problem described in (3), and factor prices are factor marginal productivities:

$$
r=f_{1}(K, L)-\delta, \quad w=f_{2}(K, L) .
$$

(iii) The goods market clears:

$$
\int[c(s, a)+z(s, a)] d \mathbf{x}+G=f(K, L)+(1-\delta) K .
$$

(iv) The government budget constraint is satisfied:

$$
G+T r=T .
$$

(v) The measure of households is stationary:

$$
\mathbf{x}(B)=\int_{B}\left(\int_{S, \mathcal{C}}\left\{\xi_{z(s, a)} \xi_{s \notin \mathbb{R} \vee s^{\prime} \notin \varepsilon}+\xi_{\left[1-\tau_{E}(z)\right] z(s, a)} \xi_{s \in \mathbb{R} \wedge s^{\prime} \in \mathcal{E}}\right\} \boldsymbol{\Gamma}_{s, s^{\prime}} d \mathbf{x}\right) d z d s^{\prime}
$$

for all $B \in \mathscr{B}$, where $\vee$ and $\wedge$ are the logical operators "or" and "and." Equation (14) counts the households, and the cumbersome indicator functions and logical operators are used to account for estate taxation. We describe the procedure that we use to compute this equilibrium in Section $B$ of the Appendix.

\section{Calibration}

In this article, we use the following calibration strategy: (i) we target key ratios of the U.S. National Income and Product Accounts, some 
TABLE 2

Distributions of Earnings and Wealth in the U.S. Economy (\%)

\begin{tabular}{|c|c|c|c|c|c|c|c|c|}
\hline \multirow[b]{2}{*}{ Gini } & \multicolumn{5}{|c|}{ Quintile } & \multicolumn{3}{|c|}{ Top Groups (Percentile) } \\
\hline & First & Second & Third & Fourth & $\overline{\text { Fifth }}$ & 90th-95th & 95th-99th & 99 th-100th \\
\hline & & & & A. Dist & bution & f Earnings & & \\
\hline \multirow[t]{2}{*}{.63} & -.40 & 3.19 & 12.49 & 23.33 & 61.39 & 12.38 & 16.37 & 14.76 \\
\hline & \multicolumn{8}{|c|}{ B. Distribution of Wealth } \\
\hline .78 & -.39 & 1.74 & 5.72 & 13.43 & 79.49 & 12.62 & 23.95 & 29.55 \\
\hline
\end{tabular}

features of the current U.S. income and estate tax systems, some descriptive statistics of U.S. demographics, and some features of the life cycle profile and of the intergenerational persistence of U.S labor earnings; ${ }^{9}$ and (ii) we also target the Lorenz curves of the U.S. distributions of earnings and wealth reported in table 2. This last feature is a crucial step in our calibration strategy, and we feel that it should be discussed in some detail.

Recall that, in Section II, we highlighted that the literature traditionally models the process on earnings using direct measurements from some source of earnings data, such as the PSID, the Current Population Survey, or even the Consumer Expenditure Survey. However, all these data sources suffer from two important shortcomings: unlike the SCF, they are not specifically concerned with obtaining a careful measurement of the earnings of the households in the top tail of the earnings distribution, and they use a significant amount of top-coding-a procedure that groups every household whose earnings are above a certain level in the last interval.

These important shortcomings have the following implications: (i) the measures of aggregate earnings obtained using those databases are inconsistent with the measures obtained from National Income and Product Accounts data, and (ii) the distributions of earnings generated by those processes are significantly less concentrated than the distribution of U.S. earnings obtained from SCF data; to verify this fact, simply compare the U.S. distribution of earnings with the distributions of earnings of the model economies reported in table $1 .{ }^{10}$ Furthermore, the

\footnotetext{
${ }^{9}$ Note that throughout this article our definition of earnings both for the United States and for the model economies includes only before-tax labor income. Consequently, it does not include either capital income or government transfers. The sources for the data and the definitions of all the distributional variables used in this article can be found in Díaz-Giménez et al. (1997).

${ }^{10}$ Note that the distributions of earnings summarized in table 1 have been generated using processes that match the main features of data sources other than the SCF.
} 
methods used to estimate the persistence of earnings using direct data are somewhat controversial. ${ }^{11}$

To get around these problems, instead of using direct estimates from earnings data, we use our own model economy to obtain a process on the endowment of efficiency labor units that delivers the U.S. distributions of earnings and wealth as measured by the SCF. As we discuss in detail below, our calibration procedure uses the Gini indexes and a small number of points of the Lorenz curves of both earnings and wealth as part of our calibration targets. This calibration procedure amounts to searching for a parsimonious process on the endowment of efficiency labor units, which, together with the remaining features of our model economy, allows us to account for the earnings and wealth inequality and for the rest of our calibration targets simultaneously.

In the subsections that follow, we discuss our choices for the model economy's functional forms and identify their parameters, we describe our calibration targets, and we describe the computational procedure that allows us to choose the values of those parameters. We report the parameter values in table 3 and in table 4 and in the first row of table 5 below.

\section{A. Functional Forms and Parameters}

\section{Preferences}

Our choice for the households' common utility function is ${ }^{12}$

$$
u(c, l)=\frac{c^{1-\sigma_{1}}}{1-\sigma_{1}}+\chi \frac{(\ell-l)^{1-\sigma_{2}}}{1-\sigma_{2}} .
$$

We make this choice because the households in our model economies face very large changes in productivity, which, under standard nonseparable preferences, would result in extremely large variations in hours worked. To avoid this, we chose a more flexible functional that is additively separable in consumption and leisure and that allows for different curvatures on these two variables. Our choice for the utility function implies that, to characterize the households' preferences, we must choose the values of five parameters: the four that identify the utility function and the time discount factor, $\beta$.

\footnotetext{
${ }^{11}$ See Storesletten, Telmer, and Yaron (1999) for a discussion of this issue.

${ }^{12}$ Note that we have assumed that retired households do not work, and consequently, the second term in expression (15) becomes an irrelevant constant for these households.
} 
TABLE 3

Parameter Values for the Benchmark Model Economy

\begin{tabular}{|c|c|c|}
\hline & Parameter & Value \\
\hline \multicolumn{3}{|l|}{ Preferences: } \\
\hline Time discount factor & $\beta$ & .924 \\
\hline Curvature of consumption & $\sigma_{1}$ & 1.500 \\
\hline Curvature of leisure & $\sigma_{2}$ & 1.016 \\
\hline \multicolumn{3}{|l|}{ Relative share of consumption and } \\
\hline leisure & $\chi$ & 1.138 \\
\hline Productive time & $\ell$ & 3.200 \\
\hline \multicolumn{3}{|l|}{ Age and employment process: } \\
\hline Common probability of retiring & $p_{e q}$ & .022 \\
\hline Common probability of dying & $1-p_{\varrho \varrho}$ & .066 \\
\hline Earnings life cycle controller & $\phi_{1}$ & .969 \\
\hline \multicolumn{3}{|l|}{ Intergenerational earnings persistence } \\
\hline controller & $\phi_{2}$ & .525 \\
\hline \multicolumn{3}{|l|}{ Technology: } \\
\hline Capital share & $\theta$ & .376 \\
\hline Capital depreciation rate & $\delta$ & .059 \\
\hline \multicolumn{3}{|l|}{ Government policy: } \\
\hline Government expenditures & $G$ & .296 \\
\hline Normalized transfers to retirees & $\omega$ & .696 \\
\hline \multirow[t]{4}{*}{ Income tax function parameters } & $a_{0}$ & .258 \\
\hline & $a_{1}$ & .768 \\
\hline & $a_{2}$ & .491 \\
\hline & $a_{3}$ & .144 \\
\hline \multicolumn{3}{|l|}{ Estate tax function parameters: } \\
\hline Tax-exempt level & $\underline{z}$ & 14.101 \\
\hline Marginal tax rate & $\overline{\tau_{E}}$ & .160 \\
\hline
\end{tabular}

2. The Joint Age and Endowment of Efficiency Labor Units Process

In Section III, we assumed that the joint age and endowment of efficiency labor units process takes values in set $S=\{\varepsilon \cup R\}$, where $\varepsilon$ and $R$ are two $J$-dimensional sets. Consequently, the number of realizations of this process is $2 J$. Therefore, to specify this process we must choose a total of $(2 J)^{2}+J$ parameters. Of these $(2 J)^{2}+J$ parameters, $(2 J)^{2}$ correspond to the transition probability matrix on $s$, and the remaining $J$ parameters correspond to the endowments of efficiency labor units, $e(s) .^{13}$

However, our assumptions about the nature of the joint age and endowment process impose some additional structure on the transition probability matrix, $\boldsymbol{\Gamma}_{S S}$. To understand this feature of our model economy better, it helps to consider the following partition of this matrix:

$$
\boldsymbol{\Gamma}_{S S}=\left[\begin{array}{ll}
\boldsymbol{\Gamma}_{\varepsilon \varepsilon} & \boldsymbol{\Gamma}_{\varepsilon \mathcal{R}} \\
\boldsymbol{\Gamma}_{R \varepsilon} & \boldsymbol{\Gamma}_{\mathcal{R}}
\end{array}\right] .
$$

In expression (16), submatrix $\boldsymbol{\Gamma}_{\varepsilon \varepsilon}$ describes the changes in the en-

${ }^{13}$ Recall that we have assumed that $e(s)=0$ for all $s \in \mathcal{R}$. 
dowments of efficiency labor units of working-age households that are still of working age one period later; submatrix $\boldsymbol{\Gamma}_{\varepsilon \mathcal{R}}$ describes the transitions from the working-age states into the retirement states; submatrix $\boldsymbol{\Gamma}_{R \varepsilon}$ describes the transitions from the retirement states into the workingage states that take place when a retired household dies and is replaced by its working-age descendant; and, finally, submatrix $\boldsymbol{\Gamma}_{\mathcal{R} R}$ describes the changes in the retirement states of retired households that are still retired one period later. In the paragraphs that follow, we describe our assumptions with respect to these four submatrices.

First, to determine $\boldsymbol{\Gamma}_{\varepsilon \varepsilon}$, we must choose the values of $J^{2}$ parameters. The reason is that we impose no restrictions on the transitions between the working-age states. Next, $\boldsymbol{\Gamma}_{\varepsilon \mathcal{R}}=p_{e e} \mathbf{I}$, where $p_{e e}$ is the probability of retiring, and $\mathbf{I}$ is the identity matrix. The reason is that we use only the last working-age shock to keep track of the earnings ability of retired households, and we assume that every working-age household faces the same probability of retiring. Consequently, to determine $\boldsymbol{\Gamma}_{\varepsilon \mathcal{R}}$, we must choose the value of one parameter. Next, $\boldsymbol{\Gamma}_{\mathcal{R} R}=p_{\varrho \varrho} \mathbf{I}$, where $1-p_{\varrho \varrho}$ is the probability of dying. The reason is that the type of retired households never changes, and we assume that every retired household faces the same probability of dying. Consequently, to determine $\boldsymbol{\Gamma}_{\mathcal{R} R}$, we must choose the value of one additional parameter. Finally, our assumptions with respect to $\boldsymbol{\Gamma}_{R \varepsilon}$ are dictated by one of the secondary purposes of this article, which is to evaluate the roles played by the life cycle profile of earnings and by the intergenerational transmission of earnings ability in accounting for earnings and wealth inequality. It turns out that these two roles can be modeled very parsimoniously using only two additional parameters.

To do this, we use the following procedure: first, to determine the intergenerational persistence of earnings, we must choose the distribution from which the households draw the first shock of their working lives. If we assume that the households draw this shock from the stationary distribution of $s \in \mathcal{E}$, which we denote $\gamma_{\varepsilon}^{*}$, then the intergenerational correlation of earnings will be very small. In contrast, if we assume that every working-age household inherits the endowment of efficiency labor units that its predecessor had at retirement, then the intergenerational correlation of earnings will be relatively large. Since the value that we target for this correlation, which is .4, lies between these two extremes, we need one additional parameter, which we denote $\phi_{1}$, to act as a weight that averages between a matrix with $\gamma_{\varepsilon}^{*}$ in every row, which we denote $\boldsymbol{\Gamma}_{R}^{*}$, and the identity matrix. Intuitively, the role played by this parameter is to shift the probability mass of $\boldsymbol{\Gamma}_{\mathbb{R} \varepsilon}^{*}$ toward its diagonal.

Second, to measure the life cycle profile of earnings, we target the ratio of the average earnings of households between ages 60 and 41 to 
that of households between ages 40 and 21. The value of this statistic in our model economies is determined by the differences in earnings ability of new workforce entrants and senior workers. If we assume that every household starts its working life with a shock drawn from $\gamma_{\varepsilon}^{*}$, then household earnings will be essentially independent of household ageexcept for the different wealth effects that result from the householdspecific bequests. In contrast, if we assume that every household starts its working life with the smallest endowment of efficiency labor units, then household earnings will grow significantly with household age. Since the value that we target for the life cycle earnings ratio, which is 1.30 , lies between these two extremes, we need a second additional parameter, which we denote $\phi_{2}$, to act as a weight that averages between $\boldsymbol{\Gamma}_{\mathcal{R} \varepsilon}^{*}$ and a matrix with a unit vector in its first column and zeros elsewhere. Intuitively, the role played by this second parameter is to shift the probability mass of $\boldsymbol{\Gamma}_{\mathcal{R} \varepsilon}^{*}$ toward its first column.

Unfortunately, the effects of parameters $\phi_{1}$ and $\phi_{2}$ on the two statistics that interest us work in different directions. Our starting point for submatrix $\boldsymbol{\Gamma}_{\mathcal{R} \varepsilon}$ is $\boldsymbol{\Gamma}_{R}^{*}$. Then, while parameter $\phi_{1}$ attempts to displace the probability mass from the extremes of $\boldsymbol{\Gamma}_{\mathcal{R}}^{*}$ toward its diagonal, parameter $\phi_{2}$ attempts to displace the mass toward its first column. ${ }^{14}$ Consequently, this very parsimonious modeling strategy might not be flexible enough to allow us to attain every desired pair of values for our targeted statistics. $^{15}$

All these assumptions imply that, of the $(2 J)^{2}+J$ parameters needed in principle to determine the process on $s$, we are left with only $J^{2}+$ $J+4$ parameters. To keep the process on $s$ as parsimonious as possible, we choose $J=4$. This choice implies that, to specify the process on $s$, we must choose the values of 24 parameters. ${ }^{16}$

\section{Technology}

In the United States after World War II, the real wage increased at an approximately constant rate-at least until 1973-and factor income shares have displayed no trend. To account for these two properties, we choose a standard Cobb-Douglas aggregate production function in capital and in efficiency labor units. Therefore, to specify the aggregate technology, we must choose the values of two parameters: the capital share of income, $\theta$, and the depreciation rate of capital, $\delta$.

\footnotetext{
${ }^{14}$ See Sec. $A$ in the Appendix for the formula that we use to compute $\boldsymbol{\Gamma}_{R \varepsilon}$ from $\phi_{1}$, $\phi_{2}$, and $\boldsymbol{\gamma}_{\varepsilon}^{*}$.

${ }^{15}$ We discuss this property of our model economy in the first paragraph of Sec. V and in the fourth paragraph of Sec. VA below.

${ }^{16}$ Note that, when counting the number of parameters that characterize the joint age and employment process, we have not yet required $\boldsymbol{\Gamma}_{S S}$ to be a Markov matrix.
} 


\section{Government Policy}

To describe the government policy in our model economies, we must choose the income and estate tax functions and the values of government consumption, $G$, of the transfers to the retirees, $\omega(s)$.

Income taxes.-Our choice for the model economy's income tax function is

$$
\tau(y)=a_{0}\left[y-\left(y^{-a_{1}}+a_{2}\right)^{-1 / a_{1}}\right]+a_{3} y .
$$

The reasons that justify this choice are as follows: (i) the first term of expression (17) is the function chosen by Gouveia and Strauss (1994) to characterize the 1989 U.S. effective household income taxes; and (ii) we add a linear term $a_{3} y$ to this function because the U.S. government obtains tax revenues from property, consumption, and excise taxes, and in our model economy we abstract from these tax sources. ${ }^{17}$ Therefore, to specify the model economy income tax function, we must choose the values of four parameters.

Estate taxes.-Our choice for the model economy's estate tax function is

$$
\tau_{E}(z)= \begin{cases}0 & \text { for } z \leq \underline{z} \\ \tau_{E}(z-\underline{z}) & \text { for } z>\underline{z} .\end{cases}
$$

The rationale for this choice is that the current U.S. estate tax code establishes a tax-exempt level and a progressive marginal tax rate thereafter. However, because of the many legal loopholes, the effective marginal tax rates faced by U.S. households have been estimated to be significantly lower than the nominal tax rates (see, e.g., Aaron and Munnell 1992). Consequently, we consider that the importance of the progressivity of U.S. effective estate taxes is of second order, and we approximate the U.S. effective estate taxes with a tax function that specifies a tax-exempt level, $\underline{z}$, and a single marginal tax rate, $\tau_{E}$. These choices imply that, to specify the model economy estate tax function, we must choose the values of two parameters.

\section{Adding Up}

Our modeling choices and our calibration strategy imply that we must choose the values of a total of 39 parameters to compute the equilibrium of our model economy. Of these 39 parameters, five describe household preferences, two describe the aggregate technology, eight describe the

\footnotetext{
${ }^{17}$ Note that this choice implies that, in our model economies, we are effectively assuming that all sources of tax revenues are proportional to income. This assumption is equivalent to assuming that our model economy's government uses a proportional income tax to collect all the non-income tax revenues levied by the U.S. government.
} 
government policy, and the remaining 24 parameters describe the joint age and endowment process.

\section{B. $\quad$ Targets}

To determine the values of the 39 model economy parameters described above, we do the following: we target a set of U.S. economy statistics and ratios that our model economy should mimic; in one case-that of the intertemporal elasticity of substitution for consumption-we choose an off-the-shelf, ready-to-use value; and we impose five normalization conditions. In the subsections below we describe our calibration targets and normalization conditions.

\section{Model Period}

Time aggregation matters for the cross-sectional distribution of flow variables, such as earnings. Short model periods imply high wealth to income ratios and are therefore computationally costly. Hence, computational considerations lead us to prefer long model periods. Since our main data source is the $1992 \mathrm{SCF}$ and since the longest model period that is consistent with the data collection procedures used in that data set is one year, the duration of each time period in our model economy is also one year.

\section{Macroeconomic Aggregates}

We want our model economy's macroeconomic aggregates to mimic the macroeconomic aggregates of the U.S. economy. Therefore, we target a capital to output ratio, $K / Y$, of 3.13 ; a capital income share of 0.376 ; an investment to output ratio, $I / Y$, of 18.6 percent; a government expenditures to output ratio, $G / Y$, of 20.2 percent; and a transfers to output ratio, $\operatorname{Tr} / Y$, of 4.9 percent.

The rationale for these choices is as follows: According to the 1992 SCF, average household wealth was $\$ 184,000$. According to the 1998 Economic Report of the President, U.S. gross domestic product per household was $\$ 58,916$ in $1992 .{ }^{18}$ Dividing these two numbers, we obtain 3.13, which is our target value for the capital-output ratio. The capital income share is the value that obtains when we use the methods described in Cooley and Prescott (1995) excluding the public sector from the computations..$^{19}$ The values for the remaining ratios are obtained using data

${ }^{18}$ This number was obtained using the U.S. population quoted for 1992 in table B-31 of the 1998 Economic Report of the President and an average 1992 SCF household size of 2.41 as reported in Díaz-Giménez et al. (1997).

${ }^{19}$ See Castañeda et al. (1998a) for details about this number. 
for 1992 from the 1998 Economic Report of the President. The value for investment is calculated as the sum of gross private domestic investment, change in business inventories, and 75 percent of the private consumption expenditures in consumer durables. This definition of investment is approximately consistent with the 1992 SCF definition of household wealth, which includes the value of vehicles but does not include the values of other consumer durables. The value for government expenditures is the figure quoted for government consumption expenditures and government gross investment. Finally, the value for transfers is the share of GDP accounted for by Medicare and two-thirds of Social Security transfers. We make these choices because we are interested in only the components of transfers that are lump-sum, and Social Security transfers in the United States are mildly progressive. These choices give us a total of five targets.

\section{Allocation of Time and Consumption}

First, for the endowment of disposable time, we target a value of $\ell=$ 3.2. The rationale for this choice is that this value makes the aggregate labor input approximately equal to one. Given this choice, we target the share of disposable time allocated to working in the market to be 30 percent..$^{20}$ Next, we choose a value of $\sigma_{1}=1.5$ for the curvature of consumption. This value falls within the range (one to three) that is standard in the literature. Finally, we want our model economy to mimic the cross-sectional variability of U.S. consumption and hours. To this purpose, we target a value of 3.0 for the ratio of the cross-sectional coefficients of variation of these two variables. These choices give us four additional targets.

\section{The Age Structure of the Population}

We want our model economy to mimic some features of the age structure of the U.S. population. Since in our model economy there are only working-age and retired households, and since the model economy households age stochastically, we target the expected durations of their working lives and retirements to be 45 and 18 years, respectively. These choices give us two additional targets.

\section{The Life Cycle Profile of Earnings}

We want our model economy to mimic a stylized characterization of the life cycle profile of U.S. earnings. As we have already mentioned, to

\footnotetext{
${ }^{20}$ See, e.g., Juster and Stafford (1991) for details about this number.
} 
measure this profile, we use the ratio of the average earnings of households between ages 60 and 41 to that of households between ages 40 and 21. According to the PSID, in the 1972-91 period, the average value of this statistic was 1.303. This choice gives us one additional target.

\section{The Intergenerational Transmission of Earnings Ability}

We want our model economy to mimic the intergenerational transmission of earnings ability in the U.S. economy. As we have already mentioned, to measure this feature we use the cross-sectional correlation between the average lifetime earnings of one generation of households and the average lifetime earnings of their immediate descendants. Solon (1992) and Zimmerman (1992) have measured this statistic for fathers and sons in the U.S. economy, and they have found it to be approximately 0.4 . This choice gives us one additional target.

\section{Income Taxation}

We want our model economy's income tax function to mimic the progressivity of U.S. effective income taxes as measured by Gouveia and Strauss (1994). Therefore, we choose our model economy's income tax function from the family of functions described by expression (17). To identify our function, we must choose the values of parameters $a_{0}, a_{1}$, $a_{2}$, and $a_{3}$. Since $a_{0}$ and $a_{1}$ are unit-independent, we use the values reported by Gouveia and Strauss for these parameters, namely, $a_{0}=$ 0.258 and $a_{1}=0.768$. The two additional targets result (i) from imposing that the shape of the model economy tax function coincides with the shape of the function estimated by Gouveia and Strauss, in spite of the change in units; and (ii) from assuming that all revenues levied from sources other than the federal income tax are proportional to income. Notice that these two targets are uniquely determined by our choices for parameters $a_{2}$ and $a_{3}$. Specifically, the first one of these targets is achieved by choosing the value of $a_{2}$ so that the tax rate levied on average household income in our benchmark model economy is the same as the effective tax rate on average household income in the U.S. economy; and the second target is achieved by choosing the value of $a_{3}$ so that the government in our model economy balances its budget, that is, by choosing $a_{3}$ so that the steady-state values of government spending, $G$, aggregate transfers, $T r$, and total tax revenues, $T$, satisfy the condition described in expression (13). These choices give us four additional targets. 


\section{Estate Taxation}

We want our model economy to mimic the tax-exempt level specified in the U.S. estate tax code, which was $\$ 600,000$ during the 1987-97 period. Since U.S. average income per household, $\bar{y}$, was approximately $\$ 60,000$ during that period, our target for the value of estates that are tax-exempt in our model economy is $\underline{z}=10 \bar{y}$. We also want our model economy's estate taxes to mimic the revenue levied in the United States through estate taxation. During the 1985-97 period, this revenue was only 0.2 percent of GDP (see, e.g., Aaron and Munnell 1992). These choices give us two additional targets.

\section{Normalization}

We have one degree of freedom to determine the units in which labor is measured. This allows us to normalize the endowment of efficiency labor units of the least productive households to be $e(1)=1.0$. Moreover, since matrix $\boldsymbol{\Gamma}_{s s}$ is a Markov matrix, its rows must add up to one. This property imposes four additional normalization conditions on the rows of $\boldsymbol{\Gamma}_{\varepsilon \varepsilon} .{ }^{21}$ Therefore, normalization provides us with five additional targets.

\section{The Distributions of Earnings and Wealth}

The conditions that we have described so far specify a total of 24 targets. Since to solve our model economy we have to determine the values of 39 parameters, we need 15 additional targets. Given our calibration strategy, these 15 targets, in principle, would be the Gini indexes and 13 additional points from the Lorenz curves of U.S. earnings and wealth reported in table 2. However, there are some additional restrictions that our parameter choices have to satisfy and that we have yet to discuss. These restrictions arise from imposing that matrix $\boldsymbol{\Gamma}_{S S}$ must be a Markov matrix and, hence, that all its elements must be nonnegative.

To do this, we equated to zero the transition probabilities that the nonlinear equation solver attempted to make negative. In our final calibration of the benchmark model economy, it turned out that only one of the transition probability parameters of the submatrix $\boldsymbol{\Gamma}_{\varepsilon \varepsilon}$ was equated to zero (see table 4 below). This gave us one additional target, and consequently, it reduced the number of target points of the Lorenz curves from 13 to 12 . Note that the number of points that we target is about three-quarters of the number of points that we report in tables

\footnotetext{
${ }^{21}$ Note that our assumptions about the structure of the matrix $\boldsymbol{\Gamma}_{S S}$ imply that, once the submatrix $\boldsymbol{\Gamma}_{\varepsilon \varepsilon}$ has been appropriately normalized, every row of $\boldsymbol{\Gamma}_{s s}$ adds up to one without our imposing any further restrictions.
} 
2, 7, 8, 11, and 14 below. In practice, instead of targeting 12 specific points, we searched for a set of parameter values such that, overall, the Lorenz curves of the model economies are as similar as possible to their U.S. counterparts.

\section{C. $\quad$ Choices}

The values of some of the model economy parameters are obtained directly because they are uniquely determined by one of our targets. In this fashion, we make $\sigma_{1}=1.5$ and $\theta=0.376 .^{22}$ Similarly, the values of the probability of retiring, $p_{e e}$, and of the probability of dying, $1-p_{\varrho e}$, are obtained directly from our targets for the durations of, respectively, working life and retirement. The values for two of the parameters of the income tax function, $a_{0}$ and $a_{1}$, were also taken directly from the values estimated by Gouveia and Strauss (1994) for the U.S. economy. Finally, our choice for the value of the endowment of time implies that $\ell=3.2$, and the normalization of the endowment of efficiency labor units implies that $e(1)=1.0$.

The values of the remaining 31 parameters are determined solving the system of nonlinear equations obtained from imposing that the relevant statistics of the model economy should be equal to the corresponding targets and that the model economy should be in a steadystate equilibrium. This last condition adds two additional unknowns and two additional equations to our tally. The unknowns are the capitallabor ratio and aggregate output, and the equations are the requirements that the values that the households take as given for these variables should be equal to the corresponding values implied by their decisions.

Therefore, the calibration of this model economy amounts to solving a system of 33 nonlinear equations in 33 unknowns. ${ }^{23}$ Unfortunately, solutions for these systems are not guaranteed to exist, and when they do exist, they are not guaranteed to be unique. Consequently, we tried many different initial parameter values and sets of weights to find the best calibration. We report the values of the 39 benchmark model economy parameters in tables 3 and 4 and in the first row of table 5 below, and we discuss the results of our calibration exercise in Section VA below.

\footnotetext{
${ }^{22}$ Note that, given our choice for the aggregate production function, the value of the capital income share is exactly $\theta$.

${ }^{23}$ Actually we solved a smaller system of 26 equations and 26 unknowns because our guess for the value of aggregate output uniquely determines the value of parameters $a_{2}$ and $\underline{z}$, because the value of $G$ is determined residually from the government budget constraint, and because the normalization of the matrix $\boldsymbol{\Gamma}_{\varepsilon \varepsilon}$ allows us to determine the values of four of the transition probabilities directly.
} 
TABLE 4

Transition Probabilities of the Process on the Endowment of Efficiency Labor Units for Working-Age Households That Remain at Working Age One Period LATER, $\boldsymbol{\Gamma}_{\varepsilon \varepsilon}(\%)$

\begin{tabular}{lrrrr}
\hline \hline & \multicolumn{3}{c}{ To $s^{\prime}$} \\
\cline { 2 - 5 } FrОм $s$ & $s^{\prime}=1$ & $s^{\prime}=2$ & $s^{\prime}=3$ & $s^{\prime}=4$ \\
\hline$s=1$ & 96.24 & 1.14 & .39 & .006 \\
$s=2$ & 3.07 & 94.33 & .37 & .000 \\
$s=3$ & 1.50 & .43 & 95.82 & .020 \\
$s=4$ & 10.66 & .49 & 6.11 & 80.51 \\
\hline
\end{tabular}

\section{Findings}

In this section we report our findings. We do this in two stages. In subsection $A$, we report the behavior of our benchmark model economy, which we have calibrated to the targets described in Section IV above. As we have already mentioned, we find that the parsimonious way in which we model the life cycle prevents our benchmark model economy from matching the targeted values for the intergenerational earnings correlation and for the life cycle earnings profile simultaneously. This finding led us to carry out two additional computational exercises, which we report in subsection $B$. The purpose of these exercises is to find out whether or not our model economy can match each one of those two targets separately. More specifically, in the first one of these exercises, we match the intergenerational correlation of earnings observed in the data in a model economy with a flat life cycle earnings profile, and in the second exercise we match the life cycle earnings profile observed in the data in a model economy in which earnings are uncorrelated across generations.

\section{A. The Benchmark Model Economy as a Theory of Inequality}

In this subsection we report the calibration results, we discuss the reasons that allow us to account for the U.S. earnings and wealth distributions almost exactly, and we assess our benchmark model economy as a theory of inequality.

The endowment of efficiency labor units process.-The procedure used to calibrate our model economy identifies the stochastic process on the endowment of efficiency labor units that determines its behavior. Since this process is an essential feature of our theory, we start this subsection with a description of it main properties.

Table 4 reports the transition probabilities on the endowments of efficiency labor units of working-age households that remain of working age one period later. Note that all rows sum up to .9778 (plus or minus 
TABLE 5

Relative Endowments of EfFiciency Labor Units, $e(s)$, AND the Stationary Distribution of Working-Age Households, $\gamma_{\varepsilon}^{*}$

\begin{tabular}{lrrrc}
\hline \hline & $s=1$ & $s=2$ & $s=3$ & $s=4$ \\
\hline$e(s)$ & 1.00 & 3.15 & 9.78 & $1,061.00$ \\
$\gamma_{\varepsilon}^{*}(\%)$ & 61.11 & 22.35 & 16.50 & .0389 \\
\hline
\end{tabular}

rounding errors) because the probability that a worker retires is .0222 . This table shows that the four shocks are persistent, and especially so the first three. Specifically, the expected durations of each of the shocks are 26.6, 17.6, 23.9, and 5.1 years, respectively. The table also shows that a household whose current shock is $s=1$ is most likely to make a transition to shock $s=2$ than to any of the other shocks. Likewise, households whose current shocks are either $s=2$ or $s=3$ are most likely to move back to shock $s=1$. Only very rarely will households whose current shock is either $s=1$ or $s=2$ make a transition to either shock $s=3$ or shock $s=4$, and when a household draws shock $s=$ 4 in any given period, it is most likely that it will draw shock $s=1$ very soon afterward.

Table 5 reports the relative endowments of efficiency labor units and the invariant measures of each type of working-age households. This table shows that a large majority of these households are of type $s=$ 1 , followed by types $s=2$ and $s=3$. It also shows that the invariant mass of type $s=4$ households is approximately one out of every 2,600. As far as their relative endowments of efficiency labor units are concerned, the hourly wages of types $s=2, s=3$, and $s=4$ households are, approximately, three, 10, and 1,000 times larger than those of $s=1$ households.

The persistence of this process and the large differences in the values of its realizations imply that if we normalize the present lifetime earnings of the type $s=1$ households to be one, the present values of the lifetime earnings of types $s=2, s=3$, and $s=4$ households are, approximately, $1.5,4.3$, and 120.1, respectively. Furthermore, these differences are persistent across generations. Specifically, the expected lifetime earnings of the descendants of retired households of each type are 1.0, 1.2, 2.6, and 53.7, respectively. These findings suggest that a large fraction of the differences in the economic performance of households may already have occurred before their members enter the labor market. ${ }^{24}$ The aggregate, distributional, and mobility implications of this process are discussed below.

The age structure of the population.-Our specification of the joint age

${ }^{24}$ See Keane and Wolpin (1997) for an empirical analysis of this issue. 
TABLE 6

Values of the Targeted Ratios and Aggregates in the United States and in the Benchmark Model Economies

\begin{tabular}{lccccccccc}
\hline \hline & $\begin{array}{c}K / Y \\
(1)\end{array}$ & $\begin{array}{c}I / Y \\
(2)\end{array}$ & $\begin{array}{c}G / Y \\
(3)\end{array}$ & $\begin{array}{c}\mathrm{Tr} / Y \\
(4)\end{array}$ & $\begin{array}{c}T_{E} / Y \\
(5)\end{array}$ & $\begin{array}{c}h \\
(6)\end{array}$ & $\begin{array}{c}\mathrm{CV}_{c} / \mathrm{CV}_{l} \\
(7)\end{array}$ & $\begin{array}{c}e_{40 / 20} \\
(8)\end{array}$ & $\begin{array}{c}\rho(f, s) \\
(9)\end{array}$ \\
\hline $\begin{array}{c}\text { Target (United } \\
\text { States) }\end{array}$ & 3.13 & $18.6 \%$ & $20.2 \%$ & $4.9 \%$ & $.20 \%$ & $30.0 \%$ & 3.00 & 1.30 & .40 \\
Benchmark & 3.06 & $18.1 \%$ & $20.8 \%$ & $4.4 \%$ & $.20 \%$ & $31.2 \%$ & 3.25 & 1.09 & .25 \\
\hline
\end{tabular}

Note. - Variable $h$ (col. 6) denotes the average share of disposable time allocated to the market. The statistic $\mathrm{CV}_{c} / \mathrm{CV}_{l}$ (col. 7) is the ratio of the coefficients of variation of consumption and of hours worked.

and endowment process allows us to match the targeted expected durations of the working life and retirement exactly. Hence, in every model economy analyzed in this article, the expected duration of the working life is 45 years, and the expected duration of retirement is 18 years.

The life cycle profile of earnings and the intergenerational transmission of earnings ability.-As we have already mentioned, we find that our parsimonious modeling of the life cycle does not allow us to match the targeted values for the intergenerational correlation of earnings and for the life cycle earnings profile simultaneously. Given this limitation, we decided to go part of the way, and we chose as compromise values 1.10 for the age-dependent earnings ratio and .25 for the intergenerational correlation of earnings. These values are, approximately, onethird and two-thirds of their U.S. economy counterparts. The rationale for these choices is that we feel that the intergenerational transmission of earnings is more closely related to inequality than the life cycle profile of earnings. We find that our benchmark model economy comes very close to matching those two compromise values (see cols. 8 and 9 of table 6). In subsection $B$ below, we shall carry out two robustness exercises that show that our model economy can account for each one of these two features of the data separately. This establishes that our findings do not depend crucially on the specific compromise choices for these two targets.

Income taxes.-As we have already discussed in Section IVB7, once parameter $a_{2}$ of the tax function proposed by Gouveia and Strauss (1994) has been appropriately normalized, the income tax function of the model economy is identical to the effective income tax function estimated by Gouveia and Strauss for the U.S. economy.

Estate taxes.-We report the estate tax revenue to income ratios in the United States and in the benchmark model economies in column 8 of table 6 . We find that these ratios are very similar in both economies.

Macroeconomic aggregates and the allocation of time and consumption.-We report the values of our aggregate targets for the United States and for the benchmark model economies in columns 1-5 of table 6 and the shares of hours worked and the ratios of the coefficients of variation of 
TABLE 7

Distributions of Earnings and of Wealth in the United States and in the Benchmark Model Economies (\%)

\begin{tabular}{|c|c|c|c|c|c|c|c|c|c|}
\hline \multirow[b]{2}{*}{ ECONOMY } & \multirow[b]{2}{*}{ GINI } & \multicolumn{5}{|c|}{ Quintile } & \multicolumn{3}{|c|}{$\begin{array}{l}\text { Top Groups } \\
\text { (Percentile) }\end{array}$} \\
\hline & & First & Second & Third & Fourth & Fifth & $\begin{array}{l}90 \text { th- } \\
95 \text { th }\end{array}$ & $\begin{array}{l}95 \text { th- } \\
99 \text { th }\end{array}$ & $\begin{array}{l}\text { 99th- } \\
100 \text { th }\end{array}$ \\
\hline & \multicolumn{9}{|c|}{ A. Distributions of Earnings } \\
\hline United States & .63 & -.40 & 3.19 & 12.49 & 23.33 & 61.39 & 12.38 & 16.37 & 14.76 \\
\hline \multirow[t]{2}{*}{ Benchmark } & .63 & .00 & 3.74 & 14.59 & 15.99 & 65.68 & 15.15 & 17.65 & 14.93 \\
\hline & \multicolumn{9}{|c|}{ B. Distributions of Wealth } \\
\hline United States & .78 & -.39 & 1.74 & 5.72 & 13.43 & 79.49 & 12.62 & 23.95 & 29.55 \\
\hline Benchmark & .79 & .21 & 1.21 & 1.93 & 14.68 & 81.97 & 16.97 & 18.21 & 29.85 \\
\hline
\end{tabular}

consumption and hours in columns 6 and 7 . We find that all these statistics are very similar in both economies.

The distribution of earnings. -We report the Gini indexes and selected points of the Lorenz curves of earnings in the United States and in the benchmark model economies in panel A of table 7. We find that the distributions of earnings are very similar in both economies. Moreover, our benchmark model economy does a significantly better job of accounting for the observed distribution of earnings than any of the previous attempts in the literature reported in table 1.

If we look at the fine print, we find that the main differences between the model economy and the data are that the share earned by the fourth quintile is smaller in the model economy than in the data and that this is compensated by the shares earned by the other quantiles, which are slightly larger in the model economy than in the data. During the course of this research, we tried different parameterizations of our model economy increasing the accuracy of these statistics at the expense of the accuracy of other calibration targets, and these changes made little difference to our overall findings. Our results lead us to conjecture that the differences between the Lorenz curves of earnings in the model economy and in the data would have been smaller if we had chosen a process on $s$ of a higher dimension.

The distribution of wealth.-We report the Gini indexes and selected points of the Lorenz curves of wealth in the United States and in the benchmark model economies in panel $\mathrm{B}$ of table 7 . We find that the benchmark model economy accounts for the U.S. distribution of wealth almost exactly and that it does a particularly good job of accounting for the top 1 percent of the distribution. Again, we find that, overall, our theory accounts for the observed wealth inequality in significantly 
TABLE 8

Distributions of Consumption in the United States and in the Benchmark Model ECONOMIES (\%)

\begin{tabular}{|c|c|c|c|c|c|c|c|c|c|}
\hline \multirow[b]{2}{*}{ ECONOMY } & \multirow[b]{2}{*}{ GINI } & \multicolumn{5}{|c|}{ Quintile } & \multicolumn{3}{|c|}{$\begin{array}{l}\text { TOP GROUPS } \\
\text { (Percentile) }\end{array}$} \\
\hline & & First & Second & Third & Fourth & Fifth & $\begin{array}{l}\text { 90th- } \\
95 \text { th }\end{array}$ & $\begin{array}{l}\text { 95th- } \\
99 \text { th }\end{array}$ & $\begin{array}{l}99 \text { th- } \\
100 \text { th }\end{array}$ \\
\hline \multicolumn{10}{|l|}{ United States: } \\
\hline Nondurables & .32 & 6.87 & 12.27 & 17.27 & 23.33 & 40.27 & 9.71 & 10.30 & 4.83 \\
\hline Nondurables+* & .30 & 7.19 & 12.96 & 17.80 & 23.77 & 38.28 & 9.43 & 9.69 & 3.77 \\
\hline \multicolumn{10}{|l|}{ Benchmark: } \\
\hline $\begin{array}{l}\text { Wealthiest } 1 \% \\
\text { excluded }\end{array}$ & .40 & 5.23 & 12.96 & 13.55 & 20.41 & 47.85 & 12.77 & 14.89 & 3.83 \\
\hline Entire sample & .46 & 4.68 & 11.58 & 12.07 & 18.68 & 52.99 & 12.82 & 13.45 & 11.94 \\
\hline
\end{tabular}

greater detail than any of the previous attempts in the literature reported in table 1.

If we look at the fine print, we find that the main differences between the model economy and the data are that the shares of wealth owned by the fifth quintile and by the ninetieth to ninety-fifth quantile are slightly higher in the model economy than in the data and that this is compensated by the shares owned by the third quintile and by the ninetyfifth to ninety-ninth quantile, which are slightly lower in the model economy than in the data. We contend that the conjecture about the dimension of $s$ discussed above is valid also in this case. We conclude that our choice of four realizations for the employment process is a good compromise between the resulting number of degrees of freedom and the accuracy in accounting for the U.S. earnings and wealth distributions.

The distribution of consumption.-We report selected points from the Lorenz curves of the distributions of consumption in the United States and in the benchmark model economies in table 8. The U.S. data pertain to 1991, and they were obtained using the sample weights of the Consumer Expenditure Survey and the consumer price index deflators. The first row of table 8 reports the U.S. distribution of nondurables, and the second row reports the U.S. distribution of nondurables plus the imputed services of consumer durables. A comparison of the numbers reported in those two rows shows that the U.S. distributions of those two measures of consumption are very similar.

The consumption share of output in our model economies is determined residually. Moreover, our target for the investment share includes 75 percent of private consumption expenditures in consumer durables. ${ }^{25}$

${ }^{25}$ Recall that we made this choice to be consistent with the SCF definition of wealth, which includes the value of vehicles but does not include the value of other consumer durables. 
Therefore, the appropriate term of comparison for our benchmark model economy statistics lies somewhere between the two measures of consumption reported for the United States in table 8.

The third row of table 8 reports the distribution of consumption that obtains when we exclude the wealthiest 1 percent of the model economy households from the sample, and the last row reports the distribution of consumption for the entire sample. The significant differences between these two distributions, and especially between their top tails, illustrate the extreme sensitivity of the inequality statistics to the oversampling of the households in the top tails and to the amount of topcoding.

A glance at the numbers reported in table 8 shows that consumption is more unequally distributed in the model economy than in the U.S. economy. It also shows that the shares of the lowest four quintiles resemble the data significantly more than those of the top quintile. Moreover, when we exclude the wealthiest 1 percent of the model economy households from the sample, the shares consumed by the households that belong to the top 1 percent of the distributions of consumption in the United States and in the model economies are almost the same.

When a comparison is being made between the distributions of consumption in the United States and in the benchmark model economies, it is important to keep in mind that we have not used the distribution of consumption as part of our calibration targets. Therefore, any similarities between the model economy and the U.S. data along this dimension can be considered to be overidentifying restrictions of our theory and further evidence of our success in accounting for the U.S. earnings and wealth inequality.

Mobility.-People do not stay in the same earnings and wealth groups forever. Consequently, a convincing theory of earnings and wealth inequality should account also for some of the features of the observed earnings and wealth mobility of households. One way to summarize this economic mobility is to compute the fractions of households that remain in the same earnings and wealth quintiles after a certain period of time, for instance, five years. We call these fractions the persistence statistics. Note that in our calibration exercise we have not targeted any of these statistics. Therefore, they are additional overidentifying restrictions of our theory.

We report the persistence statistics for the earnings and wealth quintiles of the United States and of the benchmark model economies in table $9 .{ }^{26}$ We interpret our mobility results to be an additional success

${ }^{26}$ The U.S. persistence statistics reported in table 9 are the same as those reported in Díaz-Giménez et al. (1997). The source for their raw data was the PSID. The period considered was the five years between 1984 and 1989. To construct the quintiles, they 
TABLE 9

Earnings and Wealth Persistence in the United States and in the Benchmark Model Economies: Fractions of Households That Remain in the Same Quintile after Five Years

\begin{tabular}{|c|c|c|c|c|c|}
\hline \multirow[b]{2}{*}{ ECONOMY } & \multicolumn{5}{|c|}{ Quintile } \\
\hline & First & Second & Third & Fourth & Fifth \\
\hline & \multicolumn{5}{|c|}{ A. Earnings Persistence } \\
\hline United States & .86 & .41 & .47 & .46 & .66 \\
\hline \multirow[t]{2}{*}{ Benchmark } & .76 & .55 & .65 & .80 & .80 \\
\hline & \multicolumn{5}{|c|}{ B. Wealth Persistence } \\
\hline United States & .67 & 47 & .45 & .50 & .71 \\
\hline Benchmark & .81 & .80 & .80 & .75 & .89 \\
\hline
\end{tabular}

of our theory. The reason is that there is nothing in our theory that would have made us predict that our model economy was going to match any of these statistics. In particular, our parsimonious way of modeling the life cycle makes it very difficult for our model economy to mimic this feature of the data, especially if we take into account the large role played by the life cycle in shaping economic mobility. ${ }^{27}$ This notwithstanding, both our benchmark model economy and the data display large earnings and wealth persistence, and both in our benchmark model economy and in the data the top and the lowest quintiles tend to be more persistent than the middle quintiles. We also find that, with the exception of the first earnings quintile, both earnings and wealth are more persistent in the benchmark model economy than in the U.S. economy. This was to be expected from our parsimonious modeling of the life cycle and from the already mentioned fact that much of the mobility in the data is linked to the earnings and wealth life cycles.

Overall, we consider our mobility findings to be encouraging, and we conjecture that versions of our model economy that include a more detailed specification of the age-earnings profile of households will mimic the U.S. persistence statistics significantly better.

An assessment.-We find that our benchmark model economy does an extremely good job of accounting for the U.S. earnings and wealth inequality and that it improves significantly previous results reported in the literature. We think that our findings are particularly creditworthy if we take into account our parsimonious model design and the many computational difficulties solved in this research. We are convinced that

took into account only the households that belonged to both the 1984 and the 1989 PSID samples.

${ }^{27}$ For instance, Auerbach and Kotlikoff (1987), Ríos-Rull (1996), and others find that the age-earnings profile of the households included in the PSID sample displays a clear hump shape. 
a more sophisticated implementation of the age-earnings profile of households would greatly enhance the ability of this class of model economies to address the life cycle profile of earnings, the intergenerational transmission of earnings, and the economic mobility of households simultaneously. Those enhanced models should be able to capture with enough detail the features of earnings and wealth inequality that are due to the life cycle and those that are due to the exogenous idiosyncratic shocks that are the gist of this article. Finally, we are convinced that this class of model economies will soon prove to be very useful to evaluate the distributional implications of policy, and we very much look forward to seeing the results of future research that quantifies these implications.

\section{B. Two Robustness Exercises}

Our parsimonious modeling of the life cycle does not allow us to match the intergenerational correlation of earnings and the ratio of the average earnings of households between ages 60 and 41 to that of households between ages 40 and 21 simultaneously. To find out whether or not this is an important shortcoming of our model economy, we carry out two robustness exercises. First, we attempt to mimic the observed intergenerational correlation of earnings while allowing earnings to display no life cycle profile, and then we attempt to mimic the observed life cycle earnings ratio while allowing earnings to display no intergenerational correlation. We find that the steady-state equilibrium allocations of these two model economies are very similar to those that obtain in the benchmark model economy, even though the parameter values that implement their calibrations differ somewhat. These findings lead us to conclude that, in spite of being quantitatively significant, the roles played by both the intergenerational transmission of earnings ability and the life cycle profile of earnings are not the key to accounting for the U.S. earnings and wealth inequality.

1. Accurate Intergenerational Transmission of Earnings Ability at the Expense of the Life Cycle Profile of Earnings

In this model economy, the households draw their first working life shock from four different conditional distributions in which the last working life shocks of the predecessors in their dynasties are significantly more likely than any of the other shocks. This feature allows us to match our targeted intergenerational correlation of earnings exactly: the value that we obtain for this statistic in this model economy is .40, which is the value of this statistic reported for the U.S. economy. However, this feature also implies that the distribution of the new entrants in this 
model economy is very similar to the distribution of senior working-age households. Consequently, in this model economy, the earnings process does not display any life cycle pattern, and the value that we obtain for its age-dependent earnings ratio is 1.0.

We solve this model economy using the calibration procedure described in Section IV above, and we report our findings in the rows labeled match autocorrelation in tables 10, 11, and 12. The numbers reported in those three tables show that the differences between the match autocorrelation and the benchmark model economies are very small.

2. Accurate Life Cycle Profile of Earnings at the Expense of the Intergenerational Transmission of Earnings Ability

In this model economy, every household draws its first working life shock from a distribution in which the low-productivity shocks are more likely than the high-productivity shocks. Consequently, labor earnings tend to improve with household age. This feature allows us to match the agedependent earnings ratio that we have chosen to measure the earnings life cycle exactly: the value that we obtain for this statistic in this model economy is 1.30, which is the value obtained from the PSID for the U.S. economy. However, since in this model economy every household draws its first working life shock from the same distribution, there is no intergenerational transmission of earnings ability, and the value of its intergenerational correlation of earnings is approximately zero.

We solve this model economy using the calibration procedure described in Section IV above, and we report our findings in the rows labeled match life cycle in tables 10, 11, and 12. Again, the numbers reported in those three tables show that the differences between the match life cycle and the benchmark model economies are very small.

\section{A Policy Experiment: Abolishing Estate Taxation}

In this section we quantify the steady-state implications of abolishing estate taxation. To this purpose, we study the aggregate, distributional, and mobility properties of a model economy that has exactly the same fundamentals as our benchmark economy, with the only exception that estates are not taxed. More specifically, the joint age and endowment of the efficiency labor units process, preferences, technology, the values of government expenditures and transfers, and the progressive part of the income tax functions are identical in both model economies. The only difference between them is the proportional part of the income tax functions, which we adjust in the model economy with no estate taxes so that the government budget constraint is satisfied. 
TABLE 10

Targeted Macroeconomic Ratios and Aggregates in the Model Economies

\begin{tabular}{lccccccccc}
\hline \hline & $K / Y$ & $I / Y$ & $G / Y$ & $T r / Y$ & $T_{E} / Y$ & $h$ & $\mathrm{CV}_{c} / \mathrm{CV}_{l}$ & $e_{40 / 20} \rho(f, s)$ \\
& $(1)$ & $(2)$ & $(3)$ & $(4)$ & $(5)$ & $(6)$ & $(7)$ & $(8)$ & $(9)$ \\
\hline Benchmark & 3.06 & $18.1 \%$ & $20.8 \%$ & $4.4 \%$ & $.20 \%$ & $31.2 \%$ & 3.25 & 1.09 & .25 \\
Match autocorrelation & 3.05 & $17.8 \%$ & $20.4 \%$ & $4.6 \%$ & $.20 \%$ & $31.9 \%$ & 3.12 & 1.00 & .40 \\
Match life cycle & 3.07 & $18.1 \%$ & $20.5 \%$ & $4.6 \%$ & $.20 \%$ & $31.8 \%$ & 3.15 & 1.30 & -.03 \\
\hline
\end{tabular}

NoTE-See note to table 6 .

TABLE 11

Distributions of Earnings and Wealth in the Model Economies (\%)

\begin{tabular}{|c|c|c|c|c|c|c|c|c|c|}
\hline \multirow[b]{2}{*}{ ECONOMY } & \multirow[b]{2}{*}{ GiNI } & \multicolumn{5}{|c|}{ QUiNTILE } & \multicolumn{3}{|c|}{$\begin{array}{l}\text { ToP GRoups } \\
\text { (Percentile) }\end{array}$} \\
\hline & & First & Second & Third & Fourth & Fifth & $\begin{array}{l}90 \text { th- } \\
95 \text { th }\end{array}$ & $\begin{array}{l}\text { 95th- } \\
\text { 99th }\end{array}$ & $\begin{array}{l}99 \text { th- } \\
100 \text { th }\end{array}$ \\
\hline & \multicolumn{9}{|c|}{ A. Distributions of Earnings } \\
\hline Benchmark & .63 & .00 & 3.74 & 14.59 & 15.99 & 65.68 & 15.15 & 17.65 & 14.93 \\
\hline Match autocorrelation & .63 & .00 & 4.02 & 14.45 & 15.68 & 65.85 & 15.29 & 17.74 & 14.86 \\
\hline \multirow[t]{2}{*}{ Match life cycle } & .62 & .00 & 3.71 & 14.65 & 16.66 & 64.98 & 13.79 & 18.21 & 14.45 \\
\hline & \multicolumn{9}{|c|}{ B. Distributions of Wealth } \\
\hline Benchmark & .79 & .21 & 1.21 & 1.93 & 14.68 & 81.97 & 16.97 & 18.21 & 29.85 \\
\hline Match autocorrelation & .80 & .18 & 1.12 & 1.64 & 14.25 & 82.80 & 17.38 & 18.63 & 30.00 \\
\hline Match life cycle & .80 & .18 & .98 & 2.00 & 15.22 & 81.61 & 16.21 & 19.93 & 29.58 \\
\hline
\end{tabular}

TABLE 12

Earnings and Wealth Persistence in the Model Economies: Fractions of Households That Remain in the Same Quintile after Five Years

\begin{tabular}{lccccc}
\hline \hline & \multicolumn{5}{c}{ Quintile } \\
\cline { 2 - 6 } Economy & First & Second & Third & Fourth & Fifth \\
\hline & \multicolumn{5}{c}{ A. Earnings Persistence } \\
\cline { 2 - 6 } Benchmark & .76 & .55 & .65 & .80 & .80 \\
Match autocorrelation & .76 & .57 & .65 & .79 & .81 \\
Match life cycle & .76 & .57 & .67 & .82 & .78 \\
\cline { 2 - 6 } & \multicolumn{7}{c}{ B. Wealth Persistence } \\
Benchmark & .81 & .80 & .80 & .75 & .89 \\
Match autocorrelation & .82 & .80 & .81 & .78 & .89 \\
Match life cycle & .80 & .79 & .78 & .73 & .89 \\
\hline
\end{tabular}


TABLE 13

Targeted Macroeconomic Ratios and Aggregates in the Model Economies

\begin{tabular}{|c|c|c|c|c|c|c|c|c|c|}
\hline & $\begin{array}{l}K / Y \\
(1)\end{array}$ & $\begin{array}{l}I / Y \\
(2)\end{array}$ & $\begin{array}{l}G / Y \\
(3)\end{array}$ & $\begin{array}{l}T r / Y \\
(4)\end{array}$ & $\begin{array}{l}T_{E} / Y \\
(5)\end{array}$ & $\begin{array}{c}h \\
(6)\end{array}$ & $\begin{array}{c}\mathrm{CV}_{c} / \mathrm{CV}_{l} \\
(7)\end{array}$ & $\begin{array}{c}e_{40 / 20} \\
(8)\end{array}$ & $\begin{array}{c}\rho(f, s) \\
(9)\end{array}$ \\
\hline Benchmark & 3.06 & $18.1 \%$ & $20.8 \%$ & $4.4 \%$ & $.20 \%$ & $31.2 \%$ & 3.25 & 1.09 & .25 \\
\hline No estate tax & 3.08 & $18.2 \%$ & $20.8 \%$ & $4.4 \%$ & $.00 \%$ & $31.2 \%$ & 3.27 & 1.09 & .25 \\
\hline
\end{tabular}

Note.-See note to table 6 .

Once we have solved the benchmark model economy, computing the solution to the model economy with no estate taxes amounts to solving a much simpler system of three nonlinear equations in three unknowns: the guesses for the capital-labor ratio and for aggregate output and the proportional part of the income tax. We report the statistics of this model economy in the rows labeled no estate tax in tables 13, 14, and 15.

We find that abolishing estate taxation brings about an increase in the steady-state output of 0.35 percent and an increase in the steadystate stock of capital of 0.87 percent. Along every other dimension, the differences between the benchmark and the no estate tax model economies are negligible. If anything, we find that abolishing estate taxation brings about a very small increase in wealth inequality. Specifically, the Gini index of wealth increases from 0.79 to 0.80 , and the share of total wealth owned by the top quintile increases from 81.97 percent to 82.33 percent.

We conjecture that the main reason that justifies these findings is that, given the demographics of our model economy, the role played by the estate tax rate in determining the after-tax rate of return of the economy is quantitatively very small. Moreover, the size of the effective marginal estate tax rate chosen for our model economy during the calibration process is also relatively small (17 percent), and, consequently, the changes brought about by abolishing these small estate taxes are also small.

TABLE 14

Distributions of Earnings and Wealth in the Model Economies (\%)

\begin{tabular}{|c|c|c|c|c|c|c|c|c|c|}
\hline \multirow[b]{2}{*}{ ECONOMY } & \multirow[b]{2}{*}{ Gini } & \multicolumn{5}{|c|}{ QUINTILE } & \multicolumn{3}{|c|}{ Top Groups (Percentile) } \\
\hline & & First & Second & Third & Fourth & Fifth & 90th-95th & 95th-99th & $\begin{array}{l}99 \text { th- } \\
100 \text { th }\end{array}$ \\
\hline & \multicolumn{9}{|c|}{ A. Distributions of Earnings } \\
\hline Benchmark & .63 & .00 & 3.74 & 14.59 & 15.99 & 65.68 & 15.15 & 17.65 & 14.93 \\
\hline \multirow[t]{2}{*}{ No estate tax } & .60 & .00 & 3.75 & 14.59 & 15.98 & 65.68 & 15.14 & 17.68 & 14.89 \\
\hline & \multicolumn{9}{|c|}{ B. Distributions of Wealth } \\
\hline Benchmark & .79 & .21 & 1.21 & 1.93 & 14.68 & 81.97 & 16.97 & 18.21 & 29.85 \\
\hline No estate tax & .80 & .20 & 1.18 & 1.86 & 14.42 & 82.33 & 17.80 & 18.26 & 30.29 \\
\hline
\end{tabular}


TABLE 15

Earnings and Wealth Persistence in the Model Economies: Fractions of Households That Remain in the Same Quintile after Five Years

\begin{tabular}{|c|c|c|c|c|c|}
\hline \multirow[b]{2}{*}{ ECONOMY } & \multicolumn{5}{|c|}{ Quintile } \\
\hline & First & Second & Third & Fourth & Fifth \\
\hline & \multicolumn{5}{|c|}{ A. Earnings Persistence } \\
\hline Benchmark & .76 & .55 & .65 & .80 & .80 \\
\hline \multirow[t]{2}{*}{ No estate tax } & .76 & .55 & .65 & .80 & .80 \\
\hline & \multicolumn{5}{|c|}{ B. Wealth Persistence } \\
\hline Benchmark & .81 & .80 & .80 & .75 & .89 \\
\hline No estate tax & .81 & .80 & .80 & .75 & .89 \\
\hline
\end{tabular}

\section{Concluding Comments}

In this article, we provide a theory of earnings and wealth inequality, based on the optimal choices of households with identical and standard preferences, that accounts for the U.S. earnings and wealth inequality almost exactly. We show that uninsured idiosyncratic earnings risk, retirement, altruism, and government transfers to retired households are essential ingredients of our theory since they allow us to replicate the observed earnings to wealth ratios of both the rich and the poor households simultaneously. We also show that calibrating the earnings process directly is a must if we want our model economies to replicate the observed distributions of earnings and wealth in sufficient detail.

Our findings also indicate that we can account for the earnings and wealth inequality observed in the United States without having to model the poor and the rich as being different. Instead, the poor and the rich can be thought of as being essentially the same type of people who have been subject to a different set of circumstances. ${ }^{28}$ We are convinced that these findings will have important implications for future research.

We consider this article to be a necessary first step in the formal attempt to quantify the distributional implications of fiscal policy. The study of the abolition of estate taxation reported in Section VI is only a preview of this type of quantitative exercises. We intend to take the next step in a companion paper, where we use the model economy described here to quantify the trade-offs brought about by different income tax policies.

${ }^{28}$ Fleming (1955) makes the same conjecture, but he attributes it to an unknown source. Specifically, he makes the following claim: "Somebody said that to become very rich you have to be helped by a combination of remarkable circumstances and an unbroken run of luck" (p. 60). 


\section{Appendix}

A. The Definition of Parameters $\phi_{1}$ and $\phi_{2}$

Let $p_{i j}$ denote the transition probability from $i \in R$ to $j \in \mathcal{E}$, let $\boldsymbol{\gamma}_{i}^{*}$ be the invariant measure of households that receive shock $i \in \mathcal{E}$, and let $\phi_{1}$ and $\phi_{2}$ be the two parameters whose roles are described in Section IVA2. Then the recursive procedure that we use to compute the $p_{i j}$ is as follows.

Step 1.-First, we use parameter $\phi_{1}$ to displace the probability mass from a matrix with vector $\gamma_{\varepsilon}^{*}=\left(\gamma_{1}^{*}, \gamma_{2}^{*}, \gamma_{3}^{*}, \gamma_{4}^{*}\right)$ in every row toward its diagonal, as follows:

$$
\begin{aligned}
& p_{51}=\gamma_{1}^{*}+\phi_{1} \gamma_{2}^{*}+\phi_{1}^{2} \gamma_{3}^{*}+\phi_{1}^{3} \gamma_{4}^{*}, \\
& p_{52}=\left(1-\phi_{1}\right)\left(\gamma_{2}^{*}+\phi_{1} \gamma_{3}^{*}+\phi_{1}^{2} \gamma_{4}^{*}\right), \\
& p_{53}=\left(1-\phi_{1}\right)\left(\gamma_{3}^{*}+\phi_{1} \gamma_{4}^{*}\right), \\
& p_{54}=\left(1-\phi_{1}\right) \gamma_{4}^{*}, \\
& p_{61}=\left(1-\phi_{1}\right) \gamma_{1}^{*}, \\
& p_{62}=\phi_{1} \gamma_{1}^{*}+\gamma_{2}^{*}+\phi_{1} \gamma_{3}^{*}+\phi_{1}^{2} \gamma_{4}^{*}, \\
& p_{63}=\left(1-\phi_{1}\right)\left(\gamma_{3}^{*}+\phi_{1} \gamma_{4}^{*}\right), \\
& p_{64}=\left(1-\phi_{1}\right) \gamma_{4}^{*}, \\
& p_{71}=\left(1-\phi_{1}\right) \gamma_{1}^{*}, \\
& p_{72}=\left(1-\phi_{1}\right)\left(\phi_{1} \gamma_{1}^{*}+\gamma_{2}^{*}\right), \\
& p_{73}=\phi_{1}^{2} \gamma_{1}^{*}+\phi_{1} \gamma_{2}^{*}+\gamma_{3}^{*}+\phi_{1} \gamma_{4}^{*}, \\
& p_{74}=\left(1-\phi_{1}\right) \gamma_{4}^{*}, \\
& p_{81}=\left(1-\phi_{1}\right) \gamma_{1}^{*}, \\
& p_{82}=\left(1-\phi_{1}\right)\left(\phi_{1} \gamma_{1}^{*}+\gamma_{2}^{*}\right), \\
& p_{83}=\left(1-\phi_{1}\right)\left(\phi_{1}^{2} \gamma_{1}^{*}+\phi_{1} \gamma_{2}^{*}+\gamma_{3}^{*}\right), \\
& p_{84}=\phi_{1}^{3} \gamma_{1}^{*}+\phi_{1}^{2} \gamma_{2}^{*}+\phi_{1} \gamma_{3}^{*}+\gamma_{4}^{*} .
\end{aligned}
$$

Step 2.-Then for $i=5,6,7$, and 8 , we use parameter $\phi_{2}$ to displace the resulting probability mass toward the first column as follows:

$$
\begin{aligned}
& p_{i 1}=p_{i 1}+\phi_{2} p_{i 2}+\phi_{2}^{2} p_{i 3}+\phi_{2}^{3} p_{i 4}, \\
& p_{i 2}=\left(1-\phi_{2}\right)\left(p_{i 2}+\phi_{2} p_{i 1}+\phi_{2}^{2} p_{i 4}\right), \\
& p_{i 3}=\left(1-\phi_{2}\right)\left(p_{i 3}+\phi_{2} p_{i 4}\right), \\
& p_{i 4}=\left(1-\phi_{2}\right) p_{i 4} .
\end{aligned}
$$




\section{B. Computation}

As we have described in Section IV, to calibrate our model economies, we must find the parameter values that imply that the steady-state conditions are satisfied and that the steady-state statistics come close to matching our target values. This amounts to solving a nonlinear system of 26 equations and 26 unknowns. To solve this system, we use a standard nonlinear equation solver (specifically a modification of Powell's hybrid method, implemented in subroutine DNSQfrom the SLATEC package). The equations include the steady-state equilibrium conditions for the capital-labor ratio and for aggregate output and the 24 equations that specify the steady-state values of our 24 additional targets. The unknowns include the guesses for the capital-labor ratio and for aggregate output and the values of 24 of our model economies' free parameters. ${ }^{29}$ To find a parameterization that gives us acceptable differences between the values of the model economies' statistics and the calibration targets, we must evaluate the system of equations a very large number of times. Moreover, each one of these evaluations entails computing the equilibrium of our model economy for a given set of parameter values. For each of these sets of parameter values, we use the following procedure to compute the model statistics.

Step 1.-We compute the households' decision rules. We do this using a piecewise linear approximation. The decision rule grid is very unequally spaced. The distance between the grid points is very small near the origin, and it increases rapidly as we move toward the upper bound of the set of asset holdings. The reasons are that the curvature of the decision rules decreases very rapidly in wealth and the range of asset holdings needed to achieve the observed wealth concentration is fairly large: it is the interval $(0,3,400)$. In every iteration and for every grid point, we solve the system formed by the two nonlinear Euler equations. To increase the efficiency of the computations, we exploit the monotonicity of the decision rules and their piecewise linearity. The inequality constraints that restrict the labor decision increase the complexity of this problem (see Ríos-Rull [1999] for details about the solutions of this class of problems).

Step 2.-Given the decision rules, we define and compute a Markov process for the individual state $\{s, a\}$ that satisfies the necessary conditions for the existence of a unique stationary distribution, $\mathbf{x}^{*}$ (see Aiyagari [1994] or Huggett [1995] for details). We approximate this distribution with a piecewise linearization of its associated distribution function. The grid for this approximation has 80,000 unequally spaced points that are very close to each other near the origin (see Ríos-Rull [1999] for details).

Step 3.-We compute the model economy's distributional and aggregate statistics. This step requires the computation of integrals with respect to the stationary distribution, $\mathbf{x}^{*}$. We evaluate these integrals directly using our approximation to the distribution function for every statistic except for those that measure mobility, the earnings life cycle, and the intergenerational correlation of earnings. To compute these three sets of statistics, we use a representative sample of 20,000 households drawn from $\mathbf{x}^{*}$ (once again, see Ríos-Rull [1999] for details).

${ }^{29}$ We make a change of variables to ensure that the choices that the algorithm makes of the transition probabilities are always positive and that the sign restrictions are satisfied. See the discussion in Secs. IVB10 and IVC and in n. 23. 


\section{References}

Aaron, Henry J., and Munnell, Alicia H. "Reassessing the Role for Wealth Transfer Taxes." Nat. Tax J. 45 (June 1992): 119-43.

Aiyagari, S. Rao. "Uninsured Idiosyncratic Risk and Aggregate Saving." Q.J.E. 109 (August 1994): 659-84.

Auerbach, Alan J., and Kotlikoff, Laurence J. Dynamic Fiscal Policy. New York: Cambridge Univ. Press, 1987.

Castañeda, Ana; Díaz-Giménez, Javier; and Ríos-Rull, José-Víctor. "Exploring the Income Distribution Business Cycle Dynamics.” J. Monetary Econ. 42 (August 1998): 93-130. (a)

. "A General Equilibrium Analysis of Progressive Income Taxation: Quantifying the Trade-offs.” Manuscript. Philadelphia: Univ. Pennsylvania, Dept. Econ., 1998. (b)

Cole, Hal L., and Kocherlakota, Narayana R. "Efficient Allocations with Hidden Income and Hidden Storage." Staff report. Minneapolis: Fed. Reserve Bank, Res. Dept., 1997.

Cooley, Thomas F., and Prescott, Edward C. "Economic Growth and Business Cycles." In Frontiers of Business Cycle Research, edited by Thomas F. Cooley. Princeton, N.J.: Princeton Univ. Press, 1995.

De Nardi, Mariacristina. "Wealth Inequality and Intergenerational Links." Working Paper no. 13. Chicago: Fed. Reserve Bank, Res. Dept., 1999.

Díaz-Giménez, Javier; Quadrini, Vincenzo; and Ríos-Rull, José-Víctor. "Dimensions of Inequality: Facts on the U.S. Distributions of Earnings, Income, and Wealth.” Fed. Reserve Bank Minneapolis Q. Rev. 21 (Spring 1997): 3-21.

Domeij, David, and Klein, Paul. "Accounting for Swedish Wealth Inequality." Paper no. 0883 presented at the Econometric Society World Congress, Seattle, August 13, 2000.

Fleming, Ian. Moonraker. London: Penguin, 1955.

Gouveia, Miguel, and Strauss, Robert P. "Effective Federal Individual Income Tax Functions: An Exploratory Empirical Analysis.” Nat. Tax J. 47 (June 1994): 317-39.

Huggett, Mark. "The Risk-Free Rate in Heterogeneous-Agent Incomplete-Insurance Economies." J. Econ. Dynamics and Control 17 (September-November 1993): 953-69.

- "The One-Sector Growth Model with Idiosyncratic Risk." Discussion Paper no. 105. Minneapolis: Fed. Reserve Bank, Res. Dept., 1995.

— . "Wealth Distribution in Life-Cycle Economies." J. Monetary Econ. 38 (December 1996): 469-94.

Hurst, Erik; Luoh, Ming Ching; and Stafford, Frank P. "The Wealth Dynamics of American Families, 1984-94." Brookings Papers Econ. Activity, no. 1 (1998), pp. 267-329.

Juster, F. Thomas, and Stafford, Frank P. "The Allocation of Time: Empirical Findings, Behavioral Models, and Problems of Measurement." J. Econ. Literature 29 (June 1991): 471-522.

Keane, Michael P., and Wolpin, Kenneth I. "The Career Decisions of Young Men.” J.P.E. 105 (June 1997): 473-522.

Krusell, Per, and Smith, Anthony A., Jr. "Income and Wealth Heterogeneity in the Macroeconomy." J.P.E. 106 (October 1998): 867-96.

Lillard, Lee A., and Willis, Robert J. "Dynamic Aspects of Income Mobility." Econometrica 46 (September 1978): 985-1012.

Quadrini, Vincenzo. "Entrepreneurship, Saving and Social Mobility.” Discussion 
Paper no. 116. Minneapolis: Fed. Reserve Bank, Inst. Empirical Macroeconomics, 1997.

Quadrini, Vincenzo, and Ríos-Rull, José-Víctor. "Understanding the U.S. Distribution of Wealth.” Fed. Reserve Bank Minneapolis Q. Rev. 21 (Spring 1997): 22-36.

Ríos-Rull, José-Víctor. "Life-Cycle Economies and Aggregate Fluctuations." Rev. Econ. Studies 63 (July 1996): 465-89.

—. "Computation of Equilibria in Heterogeneous-Agent Models." In Computational Methods for the Study of Dynamic Economies, edited by Ramon Marimon and Andrew Scott. Oxford: Oxford Univ. Press, 1999.

Solon, Gary. "Intergenerational Income Mobility in the United States." A.E.R. 82 (June 1992): 393-408.

Storesletten, Kjetil; Telmer, Chris; and Yaron, Amir. "Asset Pricing with Idiosyncratic Risk and Overlapping Generations." Manuscript. Philadelphia: Univ. Pennsylvania, Dept. Econ., 1999.

Wolff, Edward N. "Estimates of Household Wealth Inequality in the U.S., 1962-1983." Rev. Income and Wealth 33 (September 1987): 231-56.

Zimmerman, David J. "Regression toward Mediocrity in Economic Stature." A.E.R. 82 (June 1992): 409-29. 